\title{
Non-hypoproteinemic hypertrophic gastropathy
}

INSERM

\section{Source}

INSERM. (1999). Orphanet: an online rare disease and orphan drug data base. Nonhypoproteinemic hypertrophic gastropathy. ORPHA:329883

Non-hypoproteinemic hypertrophic gastropathy is a rare gastroesophageal disease characterized by diffusely enlarged gastric folds, excessive mucus secretion, normal serum protein and gastric T GF-alpha levels. Patients typically present anemia, abdominal pain not related to eating or bowel habits and absence of peripheral edema. 